Gut, 1974, 15, 116-120

\title{
Inhibitory effect of bromazepam on basal and betazole-stimulated gastric acid secretion in man
}

\author{
G. STACHER ${ }^{1}$ AND DORIS STÄRKER
}

From the Research Laboratory of the First Surgical and the Psychiatric University Clinic, Vienna, Austria

SUMMARY Basal, as well as betazole-stimulated gastric acid secretion in man is reduced after the intravenous administration of bromazepam. In subjects staying awake, this reduction is limited to the first two 15-minute periods. The reduction is highly significant in subjects who fall asleep after receiving the drug. Natural sleep causes the same depression. The low level of acid secretion is maintained until the subjects are awakened when there is a sharp and highly significant rise. Acid secretion in subjects who fall asleep after the simultaneous administration of betazole and bromazepam is significantly higher than after the administration of bromazepam alone. Sleep causes a much greater depression of basal and betazole-stimulated acid secretion than does the benzodiazepine itself.

Acid secretion was measured by continuous intragastric titration and a $\mathrm{pH}$-sensitive endoradiosonde.

'Maximal' acid output in response to an augmented histamine test, betazole, or pentagastrin is known to be affected by certain drugs and by vagotomy. Very little is known about the influence of the level of central and autonomic activity. Sleep was reported to cause no significant change from the waking level on unstimulated gastric secretion (Sandweiss, Friedman, Sugarman, and Podolsky, 1946; Wolf and Wolff, 1947; Levin, Kirsner, Palmer, and Butler, 1948; Reichsman, Cohen, Colwill, Davis, Kessler, Shepardson, and Engel, 1960) or to cause stimulation (Johnston and Washeim, 1924). Only a study in a child with a gastric fistula showed diminished gastric secretion during sleep (Engel, Reichsman, and Segal, 1956). Several reports exist on the influence of anaesthesia on histamine-stimulated gastric acid secretion. In dogs secretion was found to be reduced (Marks, Komarov, and Shay, 1958; Skyring et al, 1961 ; Powell and Hirschowitz, 1967) or stimulated (Schachter, 1949) and in man Merendino (1948) also observed a further stimulation.

Sleep induced by sodium pentobarbital was reported to have no influence on histamine-stimulated acid secretion (Reichsman et al, 1960). More recently, the tranquillizer diazepam was shown to diminish basal acid secretion (Berner, Neumayr, and Stacher, 1971; Birnbaum, Karmeli, and Makonnen, 1971). The purpose of this study was to assess the

'Present address: I. Chirurgische Universitätsklinik, 1090 Wien, Alserstr. 4, Austria.

Received for publication 3 December 1973. effect of another benzodiazepine, bromazepam, with or without sleep, on basal and betazole-stimulated secretion in man.

\section{Methods}

MEASUREMENT OF GASTRIC ACID SECRETION We used the method of continuous intragastric titration and an endoradiosonde (Heidelberg capsule) as an intragastric pH sensor (Stavney, Hamilton, Sircus, and Smith, 1966). The acidic gastric contents were neutralized by oral administration of $5 \mathrm{ml}$ of a molar potassium bicarbonate solution. When the original acidic $\mathrm{pH}$ was again reached a further dose of bicarbonate was given and this procedure was continued until the experiment was ended. The times between the two titrations were measured. As 5 m-equiv $\mathrm{KHCO}_{3}$ reacts with $5 \mathrm{~m}$-equiv $\mathrm{HCl}$ it was assumed that during one neutralization time $5 \mathrm{~m}$-equiv $\mathrm{HCl}$ was produced. Acid output was calculated as milliequivalents per 15 minutes.

\section{APPARATUS}

The endoradiosondes (Heidelberg capsule) are commercially available pH-sensitive radio pills. The signals from the pills are received by an antenna system and fed into a modified radio receiver able to measure not only $\mathrm{pH}$ changes as expressed in frequency shifts but also the variations in electromagnetic field strength, which shows the movements 


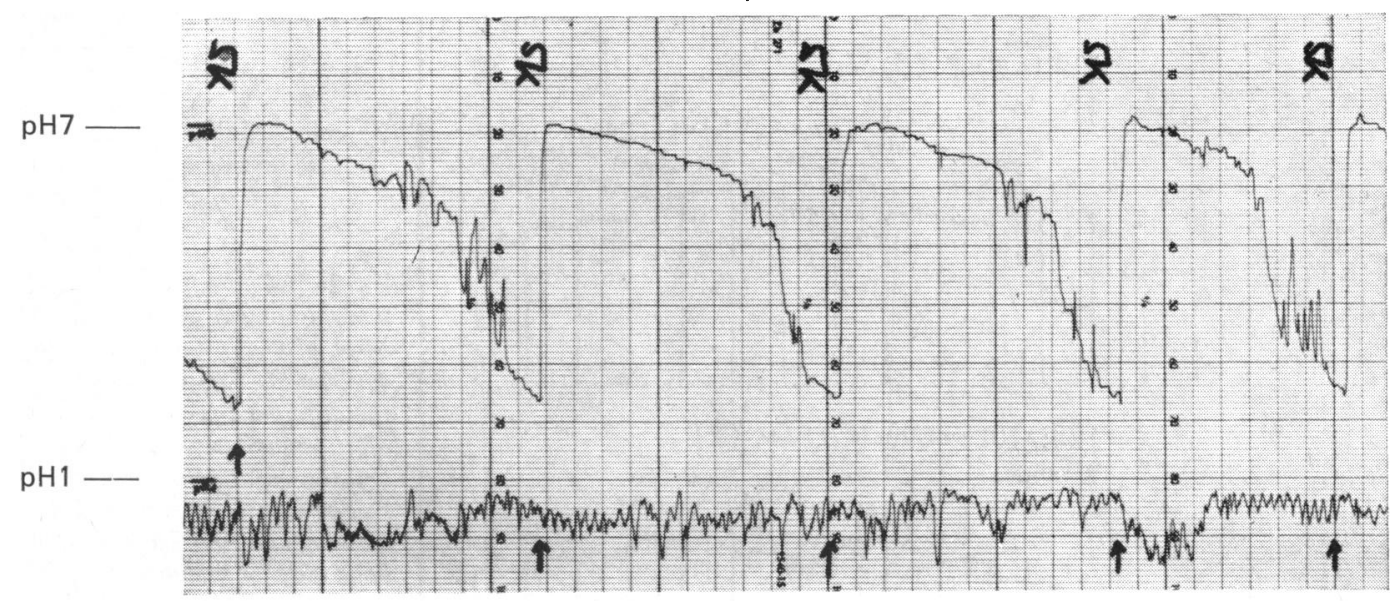

5 minutes

Fig 1 Continuous intragastric titration with the $p H$-sensitive endoradiosonde. Upper trace, $p H$, lower trace, variation of electromagnetic field strength as measure of gastric motility. Oral administration of $5 \mathrm{ml} 1 \mathrm{~m}$ $\mathrm{KHCO}_{3}$ is indicated by an arrow $(\uparrow)$.

of the pills in the stomach (fig 1). The $\mathrm{pH}$ and field strength were recorded on a two-channel writing system. All measurements were carried out in a screened room to avoid interference from high frequencies.

\section{SUBJECTS}

Six healthy students (four women and two men) who were paid for their participation, were used as subjects. They were aged from 21 to 29 years, the average being $22 \cdot 9$.

\section{PROCEDURE}

The subjects came to the laboratory at 8.00 am after a 12-hour fast. The endoradiosonde, with a thin silk thread attached to it, was swallowed and after reaching the stomach, the thread was fixed to the subject's nose to prevent the pill from gliding further 'downstream'.

During the sessions, the subjects lay on a bed in a supine or left-sided position.

After one hour of measuring basal acid secretion, the following series of experiments was done: (1) administration of $1.7 \mathrm{mg}$ per $\mathrm{kg}$ body weight betazole subcutaneously (13 tests on six subjects); (2) administration of $1.7 \mathrm{mg}$ per $\mathrm{kg}$ body weight betazole (subcutaneously) plus $0 \cdot 1 \mathrm{mg}$ per $\mathrm{kg}$ body weight bromazepam intravenously. In this series, the subjects were kept awake (10 tests on six subjects); (3) as in series 2, but the subjects were allowed to sleep after receiving the drugs (11 tests on six subjects); (4) administration of $0 \cdot 1 \mathrm{mg}$ per $\mathrm{kg}$ body weight bromazepam intravenously, and after injection, the subjects were kept awake (10 tests on six subjects); (5) administration of $0 \cdot 1 \mathrm{mg}$ per $\mathrm{kg}$ body weight bromazepam, but the subjects were allowed to sleep (11 tests on six subjects); (6) in this series, the subjects were allowed to fall into a natural sleep. Sleep was facilitated by a uniform level of noise (12 tests on six subjects); (7) in nine experiments betazole was given by intravenous infusion during natural sleep. Unfortunately, in all of these experiments, the subjects awoke eight to 15 minutes after the start of the infusion. Therefore, the results of this series could not be used.

The experiments were continued for three hours but in three experiments the time was shorter for technical reasons. In those experiments in which the subjects were allowed to fall asleep, they were awakened after two hours of sleep and the test was continued for another hour.

The results were analysed statistically by using Student's $t$ test for paired values when comparing data within the same series, and the $t$ test for unpaired values when comparing data from two different series.

\section{Results}

Acid output during the basal hour was in the same range in all six series. The level of basal secretion in our experiments was somewhat higher than in 


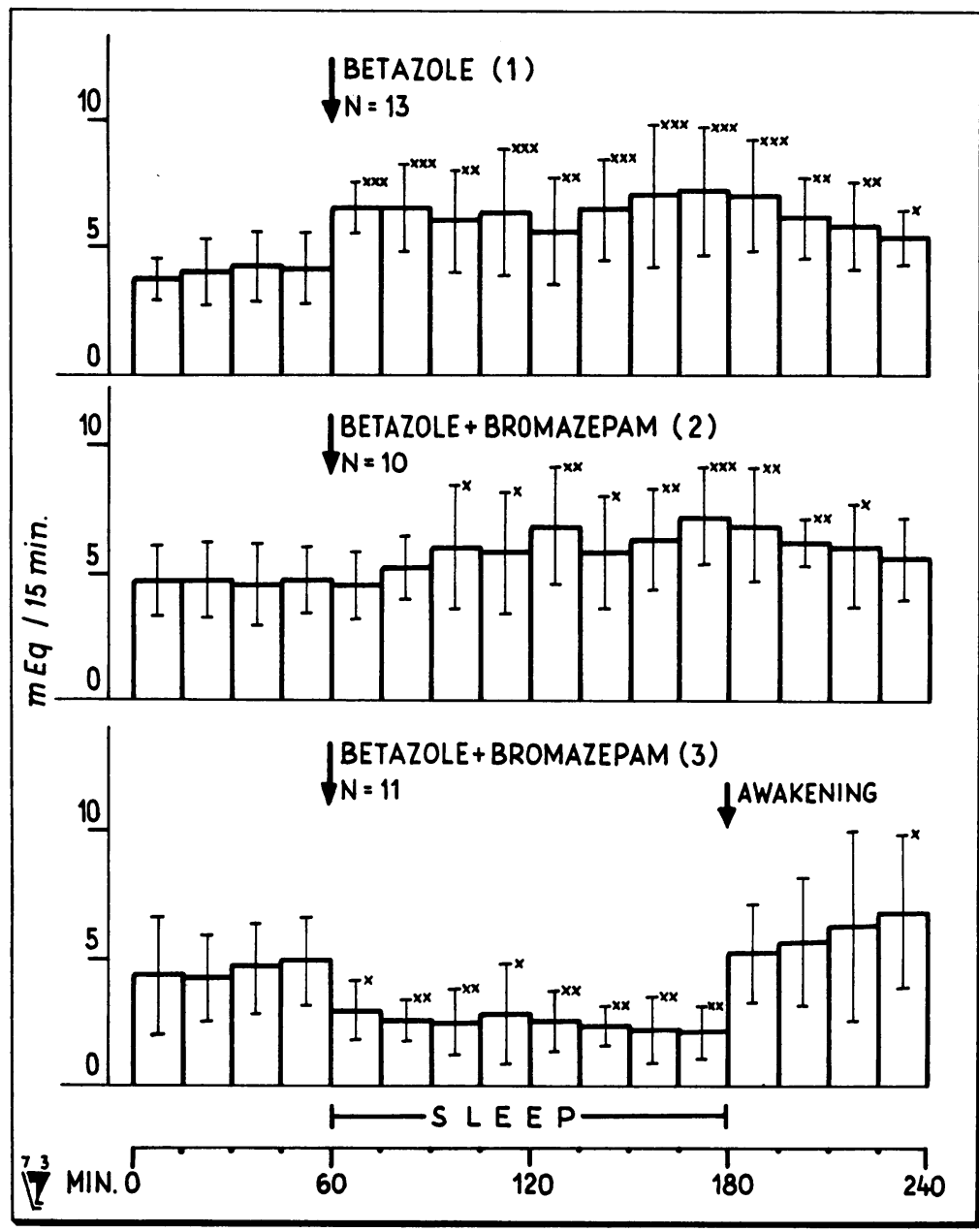

Fig 2a Acid output (m-equiv/15 minutes), mean \pm 1 standard error of mean, for series 1, 2, 3, 4,5 , and 6. The significance of the difference between each value after administration of the drug and the onset of natural sleep respectively (series 6) and the mean of the four basal quarterhour outputs is indicated. $x=\mathrm{P}<0.05, \times x, \mathrm{P}<0.01$, $\times \times \times, P<0.001$.

secretion tests carried out by the tube technique. A possible explanation of this fact is that since continuous intragastric titration involves frequent stimulation of the antrum with bicarbonate, gastric secretion is stimulated by endogenous gastrin.

\section{SERIES 1}

Administration of $1.7 \mathrm{mg}$ per $\mathrm{kg}$ body weight betazole subcutaneously led to a marked stimulation of acid secretion in all experiments which on the average lasted for two hours after injection.

SERIES 2

Simultaneous administration of $1.7 \mathrm{mg}$ per $\mathrm{kg}$ body weight betazole subcutaneously and $0.1 \mathrm{mg}$ per $\mathbf{k g}$ body weight bromazepam intraveously caused a significantly lower $(P<0.01)$ acid output during the first 15 minutes after the injections than in series 1 . In the following periods acid secretion in series 2 did not differ statistically from the values in series 1 .

\section{SERIES 3}

When the subjects fell asleep after the simultaneous administration of betazole and bromazepam a significant decrease $(\mathrm{P}<0.05)$ of acid secretion during the first 15 minutes compared with the basal hour occurred. In the following periods even less acid was produced. The low level of secretory output was maintained as long as the individuals were asleep. Wakening caused a highly significant increase $(P<0.001)$ in the four 15-minute periods which followed sleep. Acid secretion during sleep was significantly lower than in the corresponding periods of experiments in series 1 and 2 (fig 2a). 


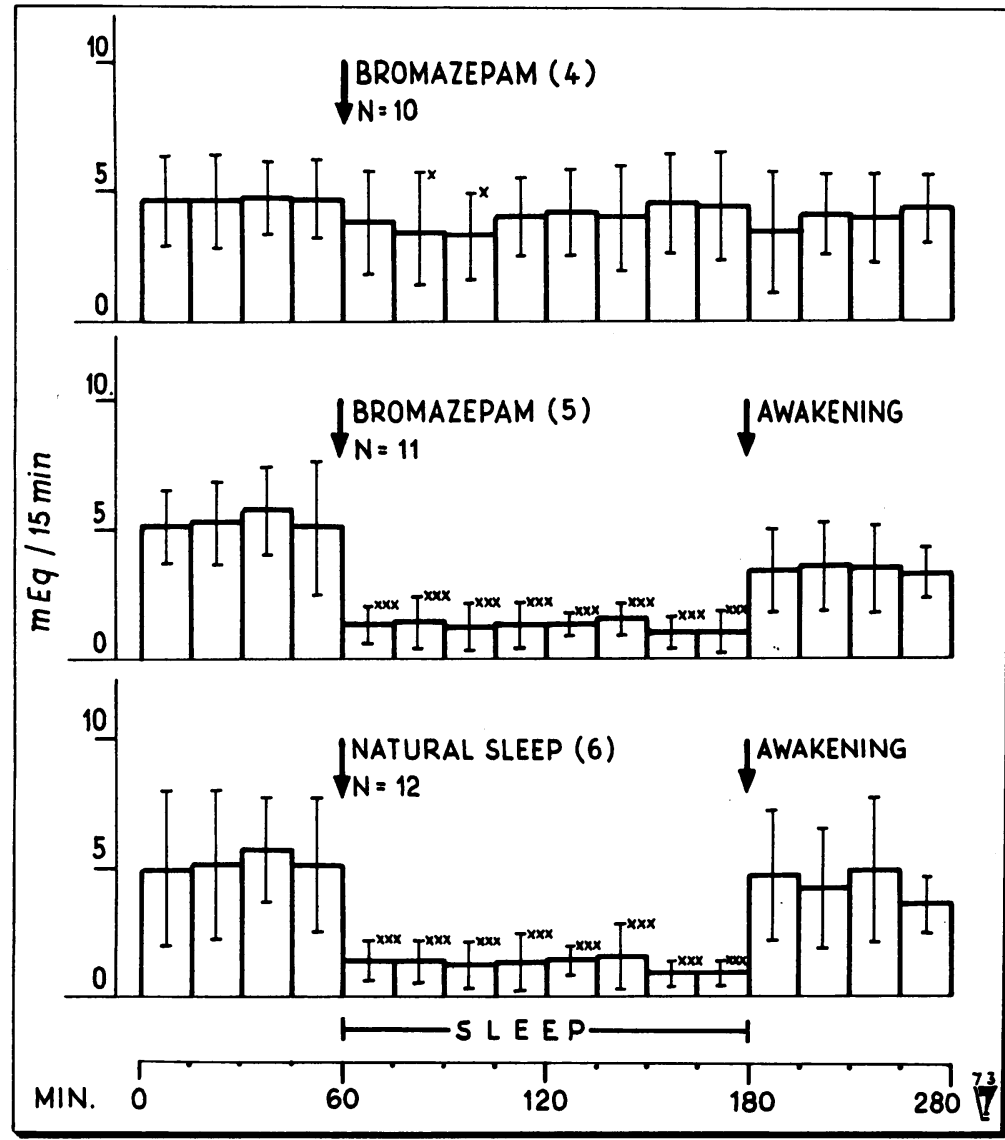

Fig 2b Acid output (m-equiv/15 minutes), mean \pm 1 standard error of mean, for series 1, 2, 3, 4,5 , and 6 . The significance of the difference between each value after administration of the drug and the onset of natural sleep respectively (series 6) and the mean of the four basal quarterhour outputs is indicated. $\times=\mathbf{P}<0.05, \times \times, \mathbf{P}<0.01$, $\times \times \times, P<0.001$,

SERIES 4

Administration of bromazepam alone caused a diminution of acid secretion compared with the basal period. In the second and third 15-minute periods after injection this difference was statistically significant $(P<0.05)$. In the second hour after injection secretion returned to the basal level.

\section{SERIES 5}

When the subjects fell asleep after the administration of bromazepam the reduction in acid secretory output compared with the basal values was highly significant $(\mathrm{P}<0.001)$. The low level was maintained as long as sleep lasted. After wakening, acid secretion rose to a significantly higher level $(P<0.001)$ than during sleep, while the original basal level was not reached again. The values of acid secretion during the sleep periods in series 5 were significantly lower ( $P<0.001)$ than during the corresponding periods in series 4 and also significantly lower $(P<0.01)$ than in series 3 (sleep after the simultaneous administration of betazole and bromazepam).

\section{SERIES 6}

After the onset of natural sleep, as in series 3 and 5, gastric acid secretion declined sharply and remained low until the subjects were awakened. In the post-sleep period acid secretion returned approximately to the basal level. During sleep, significantly less acid was produced than in series 3 , while there was no difference compared with series 5 .

Post-sleep values were significantly higher $(P<$ 0.05) in experiments with the simultaneous administration of betazole and bromazepam $(2,3)$ than in those when bromazepam $(4,5)$ alone was injected.

In figure 2 the 15-minute values of acid secretion in the six series are given.

\section{Discussion}

The pattern of change in betazole-stimulated as well as in basal acid secretion caused by bromazepam was dependent on whether the subjects fell asleep or stayed awake. Although acid output was depressed under both conditions, during sleep a significantly 
lower secretory level was observed than in individuals staying awake. This phenomenon was also observed during natural sleep. Sleep by itself seems to be a somewhat more potent inhibitor of gastric secretion than bromazepam alone. This finding is supported by the report of Stacher, Presslich, and Stärker (1973) who observed the same depression in studies on natural nocturnal sleep and EEG registration. In earlier reports no effect (Sandweiss, Friedman, Sugarman, and Podolsky, 1946; Wolf and Wolff, 1947; Levin et al, 1948) or a stimulating effect (Johnston and Washeim, 1924) of natural sleep on gastric acid secretion had been reported. Pentobarbital-induced sleep was reported to alter neither histamine-stimulated (Reichsman et al, 1960) nor unstimulated (Merendino, 1948) acid secretion in man. This discrepancy could be caused by the method used by the authors mentioned above - the classical tube method-which usually interferes with undisturbed sleep. Only Engel et al (1956), in a child with a gastric fistula, observed a diminution of gastric secretion during natural nocturnal sleep. Authors who examined the influence of anaesthetic and subanaesthetic doses of phenobarbital and pentobarbital on basal (Coffey, Koppanyi, and Linegar, 1940; Merendino, 1948; Jaffe and Friedman, 1959) and histamine-stimulated (Merendino, 1948; Marks et al, 1958; Skyring, Milton, and Maxwell, 1961 ; Powell and Hirschowitz, 1967) acid secretion in dogs tended to attribute the observed depressant effect of these drugs to a peripheral action. Our findings suggest that the cause for the diminished acid secretion during sleep, during anaesthesia, or under the influence of a tranquillizer lies more in altered central activity than in a peripheral action of the hypnotic, anaesthetic, or tranquillizing drug.

It therefore seems to us that the concept of a 'maximal' stimulation test has to be viewed critically. It does not seem justified to regard central nervous activity as a stable factor which is present in the same intensity in every 'maximal' test. Further studies on this problem may throw more light onto the relationship between peripheral stimulation and central background activity in correlating gastric acid output to other parameters of the vegetative system and to the EEG.

\section{References}

Berner, P., Neumayr, A., and Stacher, G. (1971). Angst und Magensäureproduktion. Z. Gastroent. 9, 256-265.

Birnbaum, D., Karmeli, F., and Makonnen, T. (1971). The effect of diazepam on human gastric secretion. Gut, 12, 616-618.

Coffey, R. J., Koppanyi, T., and Linegar, C. R. (1940). The effect of barbiturates on digestive secretion. Amer. J. dig. Dis., 7, 21-23.

Engel, G. L., Reichsman, F., and Segal, H. L. (1956). A study of an infant with a gastric fistula. Psychosom. Med., 18, 374-398.

Jaffe, M. E., and Friedman, M. H. F. (1959). Action of general anesthetics on gastric secretion. Fed. Proc., 18, 74.

Johnston, R. L., and Washeim, H. (1924). Studies in gastric secretion. II. Gastric secretion in sleep. Amer. J. Physiol., 70, 247-253.

Levin, E., Kirsner, J. B., Palmer, W. L., and Butler, C. (1948). The variability and periodicity of the nocturnal gastric secretion in normal individuals. Gastroenterology, 10, 939-951.

Marks, I. N., Komarov, S. A., and Shay, H. (1958). Acid secretory responses to histamine and the partial cell mass in the dog. Amer. J. Physiol., 195, 528-534.

Merendino, K. A. (1948). Pharmacological aspects of secretion. V. The effects of phenobarbital on the gastric secretions in dog and man. Gastroenterology, 10, 531-539.

Powell, D. W., and Hirschowitz, B. I. (1967). Sodium pentobarbital depression of histamine- or insulin-stimulated gastric secretion. Amer. J. Physiol., 212, 1001-1006.

Reichsman, F., Cohen, J., Colwill, J., Davis, N., Kessler, W., Shepardson, C. R., and Engel, G. L. (1960). Natural and histamininduced gastric secretion during waking and sleeping states. Psychosom. Med. 22, 14-23.

Sandweiss, D. J., Friedman, M. H. F., Sugarman, M. H., and Podolsky, H. M. (1946). Nocturnal gastric secretion. II. Studies on normal subjects and patients with duodenal ulcer. Gastroenterology, 7, 38-54.

Schachter, M. (1949). Anesthesia and gastric secretion. Amer. J. Physiol., 156, 248-255.

Skyring, A. P., Milton, G. W., and Maxwell, G. A. (1961). Effect of sodium pentobarbital on histamine-stimulated gastric secretion. Amer. J. Physiol., 201, 574-576.

Stacher, G. (1973). Zur Frage der Magensäuresekretion im Schlafe. Wien. klin. Wschr., 85, 702-706.

Stacher, G., Presslich, B., and Stärker, H. (1973). Gastric acid secretion and sleep phases during natural night sleep. (Submitted for publication).

Stavney, L. S., Hamilton, T., Sircus, W., and Smith, A. N. (1966). Evaluation of the $\mathrm{pH}$-sensitive telemetering capsule in the estimation of gastric secretory capacity. Amer. J. dig. Dis., 11, 753-760.

Wolf, S., and Wolff, H. G. (1947). Human Gastric Function, 2nd ed. Oxford University Press, London. 